\title{
KNOWLEDGE OF MEDICAL RESCUE PERSONNEL REGARDING ADVANCED RESUSCITATION PROCEDURES IN CHILDREN
}

\author{
Marcin Madziala ${ }^{1}$, Leszek Sukiennik ${ }^{2}$ \\ ${ }^{1}$ Department of Emergency Medicine, Medical University of Warsaw \\ ${ }^{2}$ Polish Society of Disaster Medicine
}

\begin{abstract}
BACKGROUND: The purpose of this study is to attempt to evaluate the knowledge of medical rescue personnel within the scope of advanced resuscitation procedures in children.

MATERIALS AND METHOD: We conducted a quantitative survey. The study included a group of 482 medical personnel. The knowledge of medical staff was assessed by their correct answers to the survey questions.

RESULTS: Especially among nurses, there was insufficient knowledge of the following issues: determination of the child's body weight (32-62\%), the second dose of amiodarone during resuscitation of the child (42-90\%), the volume of fluids used during fluid resuscitation (47-100\%).
\end{abstract}

CONCLUSIONS: Among studied groups, nurses are the worst prepared for conducting resuscitation in children. Nurses presented a low level of knowledge within the scope of advanced resuscitation procedures in children.

KEY WORDS: resuscitation, child, pharmacotherapy, course of action, medical personnel

Disaster Emerg Med J 2016; (1)1: 37-42

\section{INTRODUCTION}

Although each minute of delay in undertaking cardiopulmonary resuscitation results in lowering the chances for the patient's survival by $10-12 \%$, after 4 minutes, irreversible changes occur in the brain which are caused by anoxia [1-4]. However, in order to make resuscitation procedures effective, which would limit consequences of asphyxia, it is necessary that medical personnel understand the differences in management of paediatric patients $[5,6]$.

Systematized knowledge and awareness of the necessity to undertake resuscitation in children play an important role in early diagnostics, suitable management and eliminating complications in children in life-threatening conditions. In some countries, including Poland, during their medical studies, medical personnel undergo classes on cardiopulmonary resuscitation in adults and in children in each age group [7, 8].
Unfortunately, the professional literature does not provide reports on problems in cardiopulmonary resuscitation in children which occur in the practice of medical rescue teams. In reference to the aforementioned issue, it seems therefore to be justified to conduct research in order to evaluate the level of knowledge in medical rescue personnel within the scope of advanced resuscitation procedures in children.

The aim of the study was to evaluate the knowledge of medical rescue personnel within the scope of advanced resuscitation procedures in children.

\section{MATERIAL AND METHODS}

482 persons working in the Medical Rescue System in Poland were included in the survey. The survey was conducted within the period of January to June 2016. More specifically, 85 physicians, 140 nurs- 
es and 257 paramedics participated in this survey. The age of the respondents ranged from 21 to 65 years, while the mean age in the study group was 30.19 years $(S D \pm 7.2)$. Among the respondents, the proportion of males to females was $1: 1$. The largest group (32\%) included respondents, whose work experience was $5-10$ years.

The diagnostic poll method with a questionnaire was used in the study. The questionnaire was developed especially for the purpose of this analysis and constituted a tool in this study. It comprised a socio-demographic section (5 questions) and a core section (18 questions).

Due to the various professions involved, the evaluated persons were assigned into three groups. Group | comprised physicians $(n=85)$, group || comprised nurses $(n=140)$, while the group III comprised paramedics $(n=257)$.

Research material was encoded in Excel software and processed with the STATISTICA 10.0 statistical package. Normality in the distribution of variables was evaluated using a significance level of a $p$-value in the Kolmogorow-Smirnow test. In case of normal distribution, mean differences were evaluated with a Student-t test. For evaluation of differences among the groups, a nonparametric test was used. Statistically significant differences among the groups were calculated with a nonparametric Kruskal-Wallis test for many independent groups $(H)$. Results were assumed as statistically significant if the $p$-value was lower than 0.05 .

\section{RESULTS}

One of the first questions in the questionnaire expected those participating in this study to answer was whether they had previously taken part in training on cardiopulmonary resuscitation in children. Indeed, 296 persons, i.e. $65.5 \%$ of all respondents, declared that they had participated in a course regarding this question. The percentage of those who had completed a PALS (Paediatric Advanced Life Support) course in group I was $37 \%$, in group II - 50\%, and in group III - 76\% $(\mathrm{H}=46.2427$, $\mathrm{p}<0.001$ ). In addition, the respondents were asked whether in their opinion PALS courses should be obligatory for all medical personnel. Although 97\% respondents agreed they should, $3 \%(n=14)$ responded that they had no opinion on this subject.

This study also constituted an attempt to acquire knowledge about self-evaluation regarding the knowledge of the respondents regarding advanced resuscitation procedures in children (PALS). Respondents graded themselves using 1-5 scale, where "1" meant no knowledge, and " 5 " meant a very good knowledge. Although the mean self-evaluation of all respondents was $4.2 \pm 0.6$ points, the highest grades were self-assigned by persons from the group II (Fig. 1). Analysis revealed statistically significant differences in self-evaluation in the respective groups $(H=148.0133, p=0.000)$.

The next questions required the respondents to indicate when some assistance should be obtained while performing cardiopulmonary resuscitation on a child (as a random bystander, not as a professional on duty). The vast majority of respondents (75\%) answered correctly, indicating that firstly, a resuscitation procedure should be conducted on the child for over one minute. The highest percentage of correct answers was provided by those in group III (93\%), then by those in group I (78\%) and finally in group II $(43 \% ; H=123.8968, p=0.000)$.

The age limit between the child and the adult was known by $80 \%$ of respondents. As the other $20 \%$ responded incorrectly, they did not know that this limit is defined by pubescence. The most correct answers were provided by those in group III at 92\%. Moreover, the percentage of correct answers in group I was $75 \%$, while in group $\|-63 \%$ of persons provided correct answers $(H=46.84656, p=0.0000)$.

Respondents were also asked when 5 rescue breaths should be conducted in paediatric patients. The vast majority of respondents (95\%) would

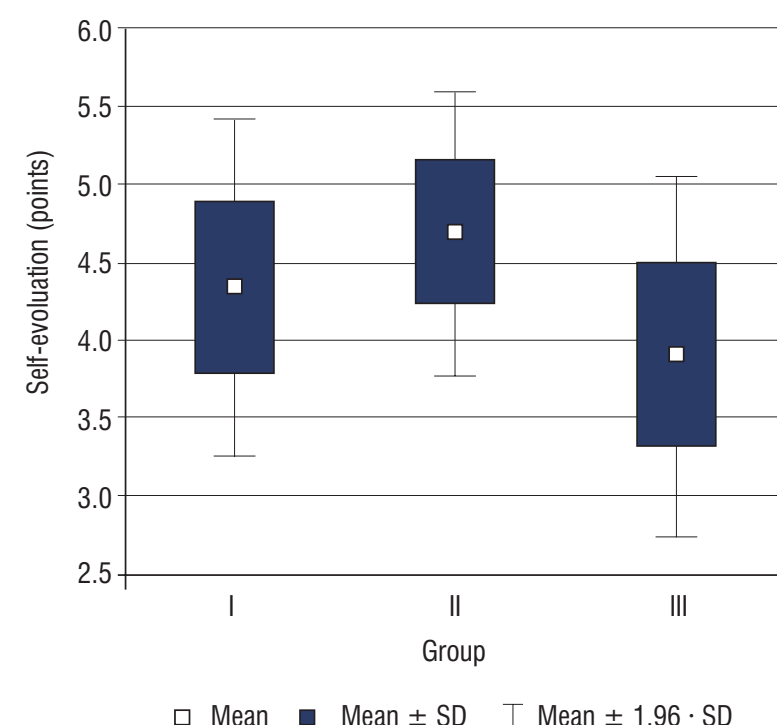

FIGURE 1. Self-evaluation knowledge of child resuscitation among research groups 
provide the child with 5 rescue breaths before the chest compressions, while the remaining $5 \%$ would provide indirect cardiac massage first. Regarding this question, similarly to the previous one, the highest percentage of correct answers was provided in the group III (100\%), then in the group I (95\%) and in the group II (86\%; $\mathrm{H}=39.02753, \mathrm{p}=0.0000)$.

Due to various rules regarding use of the drugs during resuscitation in children and in adults, the respondents were asked the approximate body weight of a 5 -year-old child. Only $53 \%$ of respondents responded in accordance with generally accepted standards and provided normal body weight of such child $(18 \mathrm{~kg})$. The percentage of correct answers was nearly the same in case of respondents in groups I and III (62\% vs. 61\%). The worst answers to this question was provided by respondents in group II (32\% of correct answers; $\mathrm{H}=34.10527, \mathrm{p}<0.0001$ ).

The term "resuscitation" was known only by nearly $89 \%$ of respondents $(n=432)$. Respondents in group I, as well as in group III stated in $99 \%$ of cases that resuscitation means return to spontaneous circulation and/or respiration. In the group of nurses, however, $67 \%$ of respondents were familiar with meaning of the term "resuscitation". Other people, who provided incorrect answers, additionally indicated the return of consciousness $(H=107.0589, p=0.000)$.

Purpose of answers to other questions was to determine knowledge within the scope of using pharmacological preparations during the resuscitation of a child. Firstly, the respondents were asked about the dose of adrenaline to be administered intravenously during CPR of a child. The correct answer, indicating $10 \mu \mathrm{g} / \mathrm{kg}$, was provided in $89 \%$ of cases $(n=414)$. Although in groups III and I, the percentage of those who gave the correct answer was $100 \%$ and $98 \%$ respectively, in group II, only $53 \%$ of persons answered this question correctly $(H=173.6360, p=0.000)$.

In subsequent questions, the respondents were expected to provide the levels of the first and second doses of amiodarone used during ventricular fibrillation/ventricular tachycardia without a pulse (VF/NT) resistant to defibrillation in paediatric patients. In case of the first dose, the correct answer $(5 \mathrm{mg} / \mathrm{kg}$ ) was provided by $81 \%$ of respondents (the percentage of correct answers was $85 \%$ in group I, 51\% in group II, and $96 \%$ in group III). The level of the second dose of amiodarone was known by fewer respondents - 74\% (group I - 80\%, group II - 42\%, group III - 90\%). An analysis revealed statistically significant differences in the correct answers provided by the respective groups, not only in reference to the first dose of amiodarone $(H=121.6351$, $p=0.000$ ), but also in the case of the second dose of amiodarone $(H=109.6446, p=0.000)$. In addition, the respondents were asked, after which ineffective defibrillation, the second dose of amiodarone should be administered (according to ERC 2010). Indeed, $74 \%$ of the respondents knew that according to the European Resuscitation Council Guidelines, the second dose of amiodarone should be administered after 5 ineffective defibrillations. However, $26 \%$ of the respondents answered incorrectly that the second dose should be administered after 3 defibrillations. Interestingly, $98 \%$ of the correct answers were provided by those in group III. The lowest percentage of correct answers was observed in group II $-38 \%(\mathrm{H}=179.9897, \mathrm{p}=0.000)$.

The respondents were also asked about the dose of atropine (according to ERC2010) recommended in children during observed ventricular fibrillation with 85\% knowing that ERC2010 guidelines do not recommend atropine administration in children during ventricular fibrillation. The highest percentage of correct answers was provided by those in group III - 94\%, with group II - 70\% and group I - $84 \%$ $(H=42.28995, p=0.0000)$.

In the next question, the respondents had to indicate the correct volume of fluids used during cardiopulmonary resuscitation in a 5-year-old child with $82 \%$ respondents identifying a correct answer of $20 \mathrm{ml} / \mathrm{kg}$. Although in group III everyone provided correct answer, along with $84 \%$ of those in group I, the correct answer was provided by only $47 \%$ of respondents in group II $(H=169.5336, p=0.000)$.

The last question required respondents to indicate the dose of energy in defibrillation recommended in a child during ventricular fibrillation. The correct dose, which is $4 \mathrm{~J} / \mathrm{kg}$, was identified by $86 \%$ of respondents. The highest percentage of correct answers were provided by those in group I (96\%), then, in group III (94\%) and, finally, in group II (70\%; $\mathrm{H}=55.96887, \mathrm{p}=0.0000)$.

Table 1 presents a comparison of the percentages of correct answers provided by the respondents to the respective questions.

\section{DISCUSSION}

Medical interventions made by medical rescue teams in cases of cardiac arrest are not rare [9-11]. Pos- 
sessing a broad knowledge of advanced resuscitation procedures, as well as skills in putting theory into practice by medical personnel, frequently determines the chances of a patient's survival. Everyone, but especially those working in the medical rescue system, should be aware that each minute of delay in undertaking rescue procedures during cardiac arrest leads to the lowering of the chances of survival of the patient by $10-12 \%[3$, $12,13]$. In order to act efficiently, as well as optimally, in situations of cardiac arrest, a "chain of survival" has been created that includes four necessary links for the management of such patients [12]. The last link refers to actions conducted by the medical personnel - i.e. advanced resuscitation procedures. Those working in medical rescue teams should have the most recent knowledge within the scope of resuscitation not only regarding adults, but also children as "the child is not a little adult." Thus, resuscitation procedures in children differ from those actions required in the case of adults, and result from differences in physiology, anatomy, or in the pathophysiology of the cardiac arrest [3].

As was mentioned in the introduction, unfortunately, the professional literature rarely provides reports on problems encountered in cardiopulmonary resuscitation in children which occurred in the practice of medical rescue personnel. In reference to aforementioned issue, it is difficult to compare results coming from this study's material with the publications of other authors.
Self-evaluation of the medical rescue personnel in studied material was assessed as good at 4.2 points. Although nurses evaluated themselves in terms of knowledge at the highest level (4.69 points), paramedics evaluated themselves at the lowest level (3.9 points). However, it should be mentioned that in case of the group of nurses, there was a significant difference between self-evaluation and results obtained in the test knowledge test. Thus, it may be assumed that the nurses overestimated their knowledge. In case of paramedics, as well as physicians, their self-evaluation was lower that their actual knowledge.

The key element related to medical profession, including physicians, nurses and paramedics, is the continuous improvement of one's medical knowledge. Indeed, 65.5\% those in the study group had participated in courses related to advanced resuscitation procedures in children. The results obtained in this study are higher than the results obtained in studies carried out by Goddet et al., who determined participation in courses related to resuscitation procedures in children at a level of 51.3\% [14]. Most often, these courses were attended by paramedics (76\%). This relationship is also confirmed by a study carried out by Waisman [15]

In medical practice, it is very important to use professional vocabulary and appropriate terms. This is also the case in resuscitation. The terms "resuscitation" and "reanimation" are interchangeably

\begin{tabular}{|c|c|c|c|}
\hline Question & $\begin{array}{l}\text { Group I } \\
(n=85)\end{array}$ & $\begin{array}{l}\text { Group II } \\
(n=140)\end{array}$ & $\begin{array}{l}\text { Group III } \\
(n=257)\end{array}$ \\
\hline Participation in training regarding advanced resuscitation procedures in children & $37 \%$ & $50 \%$ & $76 \%$ \\
\hline Should PALS training be obligatory for the medical personnel? & $90 \%$ & $96 \%$ & $100 \%$ \\
\hline Age limit between child/adult & $75 \%$ & $63 \%$ & $92 \%$ \\
\hline Moment to provide 5 rescue breaths & $95 \%$ & $86 \%$ & $100 \%$ \\
\hline Defining body weight of a child based on age & $62 \%$ & $32 \%$ & $61 \%$ \\
\hline Familiarity with term "resuscitation" & $99 \%$ & $67 \%$ & $99 \%$ \\
\hline The dose of adrenalin during CPR in a child & $98 \%$ & $53 \%$ & $100 \%$ \\
\hline The first dose of amiodarone in VTNT resistant to defibrillation & $85 \%$ & $51 \%$ & $96 \%$ \\
\hline The second dose of amiodarone in VT/NT resistant to defibrillation & $80 \%$ & $42 \%$ & $90 \%$ \\
\hline $\begin{array}{l}\text { Moment of administration of the second dose of amiodarone in VT/NT resistant } \\
\text { to defibrillation }\end{array}$ & $60 \%$ & $38 \%$ & $98 \%$ \\
\hline The dose of atropine during ventricular fibrillation in children & $84 \%$ & $70 \%$ & $94 \%$ \\
\hline Volume of fluid during fluid resuscitation in children & $84 \%$ & $47 \%$ & $100 \%$ \\
\hline Defibrillation energy dose for a child & $96 \%$ & $70 \%$ & $94 \%$ \\
\hline
\end{tabular}


used - which undoubtedly is a mistake due to the different final outcome of these procedures. Although the groups of physicians and paramedics knew the definition of "resuscitation" in $99 \%$ of cases, it was known only by $67 \%$ of persons in the group of nurses. Analysis of the research material demonstrated that nurses frequently confuse the meanings of "resuscitation" and "reanimation". In similar studies, which evaluated the knowledge of dentists in San Paulo, only $60 \%$ of respondents were able to define expression "resuscitation" [16].

In this survey, knowledge regarding age limit between the adult and the child was checked (which had been shifted from eight years of age to pubescence). Indeed, the age limit between a child and an adult was known only by $80 \%$ of the respondents. This knowledge is important, as it is used to qualify the patient to a suitable age group in order to start resuscitation using an algorithm either for adults or for children. Studies conducted by Goddet et al. showed that the level of knowledge regarding the child/adult age limit was at a level of $30.3 \%[14]$.

Doses of medicines used during cardiopulmonary resuscitation in adults and in children vary [4]. Although in the case of adults, the doses are clearly defined (e.g. $1 \mathrm{mg}$ of adrenalin), in children, these doses have to be calculated based on their body weight. During paediatric training, a common formula is used which helps to calculate average body weight in children based on their age, namely: "(age [in years] x 2) +8 ". This rule was known by $53 \%$ of the respondents. Although physicians and paramedics answered correctly in $62 \%$ and $61 \%$ of cases, respectively, the worst group comprised nurses, who achieved a corrected answer score of $32 \%$.

Doses of pharmacological preparations used in resuscitation are precisely defined and they result from assumptions based on medical facts (EBM) $[2,12]$. In case of using adrenalin, this dose is $10-30 \mu \mathrm{g} / \mathrm{kg}$ of body weight. In studies conducted by Goddet, the dose of adrenalin was known only by $89.3 \%$ respondents [14], while in studies conducted by Heitmiller, this percentage was comparable, amounting to $89 \%$ [17]. This study also demonstrated an overall result at a level of $83.6 \%$ - for example, in the group of paramedics, this dose was known by $100 \%$ of respondents, and in the group of physicians - by $98 \%$. However, in the group of nurses, percentage of correct answers was 53\%. A lack of knowledge in the group of nurses regarding pharmacotherapy in the resuscitation of children was also confirmed by the subsequent questions regarding doses of medicines. In case of the first dose of amiodarone in children, which is used in VF/VT (ventricular fibrillation/ventricular tachycardia without a pulse) resistant to defibrillation, this is $5 \mathrm{mg} / \mathrm{kg}$ of body weight. This fact was known by $51 \%$ of respondents in the group of nurses (physicians - 85\%; paramedics - 96\%). Similarly, the nurses have little knowledge regarding the second dose of amiodarone $(42 \%$ - correct answers in the group of nurses), as well as after how many inefficient defibrillations, the second dose of amiodarone should be administered (38\%) (Heitmiller - 73\% [17], Rojas - 12\% [18]).

In cases of the occurrence of ventricular fibrillation or ventricular tachycardia without a pulse, the treatment of choice includes defibrillation performed as soon as possible. Studies conducted by Goddet et al. demonstrated that the level of energy recommended for defibrillation was known by $57.2 \%$ persons [14]. Other authors obtained the following results: Heitmiller - 49\% [17], Durojaiye $-61 \%$ [19]. Our own study demonstrated that $97 \%$ of persons knew the energy dose recommended for defibrillation in children, which is $4 \mathrm{~J} / \mathrm{kg}$ of one's body weight. Although in the group of physicians, as well as in the group of paramedics, everyone provided correct answer, in the group of nurses, only $85 \%$ of persons answered correctly.

Fluid resuscitation also constitutes an important issue regarding advanced resuscitation procedures. Moreover, supplementing the vascular bed plays an important role [19]. The correct volume of fluids for transfusion in children was known by $73 \%$ of all respondents. Although in the group of physicians, $86 \%$ of respondents provided correct answers, and $78 \%$ in the group of paramedics, this amounted to only $48 \%$ in the group of nurses. Durojaiye et al. determined percentage of correctly used fluid resuscitation at the level of $52 \%$ [20].

\section{CONCLUSIONS}

Training within the scope of advanced resuscitation procedures in children for medical rescue personnel should be organized on regular basis, and familiarity with one's knowledge and skills should be verified. 
Among the evaluated professional groups, nurses are the least prepared for managing the resuscitation of a child.

Nurses displayed a low level of knowledge regarding advanced resuscitation procedures in children.

\section{Conflict of interest: None declared.}

\section{REFERENCES}

1. Biarent $D$, Bingham $R$, Eich $C$ et al. European Resuscitation Council Guidelines for Resuscitation 2010 Section 6. Paediatric life support. Resuscitation, 2010; 81(10): 1364-1388. doi: 10.1016/j.resuscitation.2010.08.012.

2. Bingham R. Evidence based paediatric resuscitation. Paediatr Anaesth, 2001; 11(1): 1-2.

3. Kleinman ME, Chameides L, Schexnayder SM et al. Part 14: pediatric advanced life support: 2010 American Heart Association Guidelines for Cardiopulmonary Resuscitation and Emergency Cardiovascular Care. Circulation, 2010; 122(18 Suppl 3): S876-908. doi: 10.1161/ CIRCULATIONAHA.110.971101.

4. Sandroni C, Nolan J. ERC 2010 guidelines for adult and pediatric resuscitation: summary of major changes. Minerva Anestesiol, 2011; 77: 220-226.

5. Bertoglio VM, Azzolin K, de Souza EN, Rabelo ER. Training in cardiopulmonary resuscitation: impact on the theoretical knowledge of nurses. Rev Gaucha Enferm, 2008; 29(3): 454-460.

6. Brown TB, Dias JA, Saini D et al. Relationship between knowledge of cardiopulmonary resuscitation guidelines and performance. Resuscitation, 2006; 69(2): 253-261.

7. Parotto $M$, Doglioni $N$, Micaglio $M$ et al. Efficacy of the neonatal resuscitation program (NRP) course on knowledge retained by residents: comparison among pediatrics, anesthesia and gynecology. Resuscitation, 2010; 81(12): 1741-1742. doi: 10.1016/j.resuscitation.2010.09.013.

8. Phillips BM, Mackway-Jones K, Jewkes F. The European Resuscitation Council's paediatric life support course 'Advanced Paediatric Life Support'. Resuscitation, 2000; 47(3): 329-334.

9. Cu J, Phan P, O'Leary FM. Knowledge and attitude towards paediatric cardiopulmonary resuscitation among the carers of patients attending the Emergency Department of the Children's Hospital at Westmead. Emerg Med Australas, 2009; 21: 401-406.
10. Kyriakou F, lacovidou N, Garofalakis I. Residents' resuscitation training and theoretical knowledge in a Greek General Hospital. Eur J Emerg Med, 2011; 18(1): 34-37. doi: 10.1097/MEJ.0b013e32833b02e4.

11. Galinski M, Loubardi N, Duchossoy MC, Chauvin M. In-hospital cardiac arrest resuscitation: medical and paramedical theory skill assessment in a university hospital. Ann Fr Anesth Reanim, 2003; 22(3): 179-182.

12. Jevdjić J, Surbatović M, Stanković N. Major changes in the European Resuscitation Council Guidelines for Cardiopulmonary Resuscitation 2010 in the field of adult basic and advanced life support. Vojnosanit Pregl, 2012; 69(3): 265-269.

13. Link MS, Atkins DL, Passman RS et al. Part 6 : electrical therapies: automated external defibrillators, defibrillation, cardioversion, and pacing: 2010 American Heart Association Guidelines for Cardiopulmonary Resuscitation and Emergency Cardiovascular Care. Circulation, 2010; 122 (18 Suppl 3): S706-719. doi: 10.1161/CIRCULATIONAHA.110.970954.

14. Goddet NS, Lode N, Descatha A et al. National evaluation of knowledge and practice of cardiopulmonary resuscitation of children and infants in the field. Ann Fr Anesth Reanim, 2009; 28(11): 943-948. doi: 10.1016/j.annfar.2009.09.011.

15. Waisman Y, Amir L, Mimouni M. Does the pediatric advanced life support course improve knowledge of pediatric resuscitation? Pediatr Emerg Care, 2002; 18(3): 168-170.

16. Gonzaga HF, Buso L, Jorge MA et al. Evaluation of knowledge and experience of dentists of San Paulo State, Brazil about cardiopulmonary resuscitation. Braz Dent J, 2003; 14(3): 220-222.

17. Heitmiller ES, Nelson KL, Hunt EA et al. A survey of anesthesiologists' knowledge of American Heart Association Pediatric Advanced Life Support Resuscitation Guidelines. Resuscitation, 2008; 79(3): 499-505. doi: 10.1016/j.resuscitation.2008.07.018.

18. Rojas L, Aizman A, Arab JP et al. Basic cardiopulmonary resuscitation: knowledge, practical skills and effectiveness of maneuvers of general physicians. Rev Med Chil, 2012; 140(1): 73-77. doi: /S003498872012000100010.

19. Smereka J, Madziała M, Szarpak L. Are firefighters able to perform intraosseous access and start fluid resuscitation in an anaphylactic patient? Am J Emerg Med, 2016; 34(8): 1707-1708. doi: 10.1016/ j.ajem.2016.05.068.

20. Durojaiye L, O'Meara M. Improvement in resuscitation knowledge after a one-day paediatric life-support course. J Paediatr Child Health, 2002; 38(3): 241-245. 